\title{
CORRECTION
}

\section{Correction to: Prof. Dr. Luther W. Brady verstorben}

\section{Hans-Peter Heilmann ${ }^{1}$}

Online publiziert: 14. November 2018

(c) Springer-Verlag GmbH Germany, part of Springer Nature 2018

\section{Correction to:}

\section{Strahlenther Onkol 2018}

https://doi.org/10.1007/s00066-018-1353-8

Leider ist uns im Nachruf auf Professor Dr. Luther W. Brady bei der Nennung der Ehrendoktorwürden ein Fehler unterlaufen.

Die korrekte Nennung der Ehrendoktorwürden lautet folgendermaßen:

Neben zwei amerikanischen Ehrendoktorwürden war er auch Ehrendoktor der Universität Heidelberg.

Wir bitten dieses Versehen zu entschuldigen.

$\triangle$ Prof. Dr. med. Hans-Peter Heilmann

hp.heilmann@gmx.de

1 Alte Landstr. 220, 22391 Hamburg, Deutschland 
Hier steht eine Anzeige.

Springer 